\title{
Dietary fiber and obesity management - a review
}

\begin{abstract}
Dietary fiber is heterogeneous and indigestible plant subunit, which has been widely used as a complementary or alternative agent in obesity management while obesity is considered as a risk factor for morbidity and mortality. At present times, reduction in fiber intake has been surprisingly found due to change in food habit and life style, even the amount is so far below the recommended level. Recently, extracted fibers from plant sources have been incorporated into meal whereas the benefits include not only obesity management but also management of cardiovascular diseases, blood sugar, digestive and general illness. This paper focuses a review on the role of different types of dietary fiber and supplements on body weight and obesity management.
\end{abstract}

Keywords: dietary fiber, obesity, weight management, soluble fiber, insoluble fiber
Volume 7 Issue 3 - 2017

\author{
Manobendro Sarker,' Maksudur Rahman ${ }^{2,3}$ \\ 'Department of Food Engineering and Technology, State \\ University of Bangladesh, Bangladesh \\ ${ }^{2}$ Department of Agricultural and Industrial Engineering, Hajee \\ Mohammad Danesh Science and Technology University, \\ Bangladesh \\ ${ }^{3}$ School of Agriculture and Biology, Shanghai jiao Tong University, \\ China
}

Correspondence: Manobendro Sarker, Lecturer, Department of Food Engineering and Technology, State University of Bangladesh, Mobile +880173/410727,

Emailmanob08@gmail.com

\section{Introduction}

Physiological description of fiber implies that dietary fiber is a plant subunit that is not being degraded to absorbable subunits in the small intestine by alimentary enzymes found in human beings. ${ }^{1}$ Generally, dietary fibers are non-starch polysaccharides including cellulose, hemicellulose, lignin, pectin, gum and mucilage and non-polysaccharide (lignin). Health benefits of the consumption of fiber rich foods ranging from prevention and treatment of obesity, reduction of blood glucose and cholesterol level, glycemic regulation, and prevention of intestinal diseases, like constipation, hemorrhoid, diverticular disease and colon cancer. ${ }^{2}$ According to recommended dietary allowances (RDA), the dietary fiber of $35 \mathrm{~g} /$ day is recommended for healthy adults. ${ }^{3}$ A recent study shows the gradual reduction of dietary fiber consumption and much lower intake of dietary fiber $25 \mathrm{~g} /$ day in Western countries has been reported. ${ }^{4}$ On the contrary, epidemiologic and cross-sectional studies indicate that lower intake of dietary fiber is associated with obesity development. ${ }^{5}$

Obesity is one of the risk factors for morbidity and mortality including type 2 diabetes, cardiovascular, osteoarthritis, malignant and metabolic diseases while the number of obese people is increasing with time. ${ }^{6}$ Nguyen et al., ${ }^{7}$ reported that approximately 1.5 billion adults are overweight or obese around the world, and obesity is being concerned as a global epidemic. ${ }^{8}$ It is clear that obesity is a medical issue, which results in more cost on health care systems in both developing and developed countries. ${ }^{9}$ Moreover, treating obesity through weight management is very important but notoriously difficult. According to the nutritional point of view, there is an association between dietary fiber intake and weight management. In this article, we emphasize on the role of dietary fiber intake regarding obesity management.

\section{Role of fiber in weight management}

\section{Properties of dietary fiber}

Dietary fiber is a diverse group of polysaccharides and each of them has a unique chemical structure with distinguishing physical properties, like water-holding capacity, adsorption, fermentability, and viscosity. Physiologic behavior of fiber largely depends on both of chemical structure and physical properties. ${ }^{10}$ A simpler classification of dietary fiber based on solubility and fermentability is shown in Table 1. According to Galisteo et al., ${ }^{11}$ short chain fatty acids from colonic fermentation of soluble fiber possess beneficial effects on lipid metabolism with cardiovascular disease prevention, mucosal differentiation and mucosal barrier function. In contrast, insoluble fibers have low fermentability with passive water-attracting properties that promote the fecal bulk, softening \& laxation. ${ }^{12}$

Table I Different types of dietary fiber. ${ }^{13,14}$

\begin{tabular}{llll}
\hline Name & Solubility & Fermentability & Source \\
\hline Cellulose & Insoluble & Slow degradation & All plant cell walls \\
Hemicellulose & Insoluble/soluble & Quick degradation than cellulose & Matrix of all plant cell walls \\
Lignin & Insoluble & No degradation & Woody plant tissue \\
Pectin & Soluble & Rapid degradation & Ripe fruits \\
Gum & Soluble/dispersible & Rapid degradation & Legumes \\
Mucilage & Soluble/dispersible & Rapid degradation & Seeds \\
\hline
\end{tabular}




\section{Dietary fiber intake and weight management}

Several epidemiological studies show an inverse relationship between dietary fiber intake and weight $\operatorname{loss}^{15,16}$ that is strongly supported by cross-sectional studies. Drewnowski ${ }^{17}$ stated that fiber content has a great impact on the palatability of food and possibly reduces energy intake. Liu et al., ${ }^{18}$ observed an inverse correlation between whole-grain ingestion and change in body weight of middleaged women. In many studies, greater satiety due to an intake of dietary fiber has been reported compared with simple sugars and digestible polysaccharides. ${ }^{19}$ Pereira et al., ${ }^{20}$ stated several factors of greater satiety, like modulation of gastric motor function, blunting of postprandial glucose and insulin response and physical properties of fiber including viscosity, gel formation and bulking. Fibers have the ability to displace the energy from other nutrients by adding bulk and weight to the meal. Likewise, fiber-rich diets achieving through fiber incorporation into meals result in low energy density compared with high-fat diets. ${ }^{20}$ Although fiber is an invisible component in any food, it is becoming the most appreciated ingredient for incorporating into meals. According to Solan, ${ }^{21}$ fiber has been ranked number five among the top functional food concepts in 2007. Now, dietary fibers from different sources, like apple, pea, citrus fruit, sugar beet and soy are popular to incorporate into meal for their nutritional, functional and technological properties.

\section{Weight management through consumption of fruits and vegetables}

Fruits and vegetables contribute both of soluble and insoluble fibers to the meal. Insoluble fibers including lignin, cellulose, and hemicellulose are found in cell wall and skin of fruits and vegetables while soluble fibers, like pectin, gum and mucilages are mostly found in skin. ${ }^{22}$ It has been reported that consumption of both soluble and insoluble fibers increase satiety. Howarth et al. ${ }^{19}$ stated that decrease in energy density by $10 \%$ and weight loss of $1.9 \mathrm{~kg}$ over 3.8 months resulted from the consumption of additional fiber $14 \mathrm{~g} /$ day. Considering previous findings it is undoubtedly true that increased consumption of fruits and vegetables would reduce energy density and body weight.

Energy density is the amount of energy exerted by a food (kcal/g or $\mathrm{kJ} / \mathrm{g}$ ) where fat is the most energy dense nutrient ( $9 \mathrm{kcal} / \mathrm{g}$ ) compared with carbohydrate $(4 \mathrm{kcal} / \mathrm{g})$ and protein $(4 \mathrm{kcal} / \mathrm{g})$. Most of the fruits and vegetables contain a high amount of water and low-fat content consequently, they possess low energy density. ${ }^{22}$ Several researchers have developed an inverse relationship between the addition of fruits and vegetables to meal and energy density ${ }^{23,24}$ Moreover, an addition of fruits and vegetables to the meal enhances satiety due to the higher moisture content and low energy density.

\section{Conclusion}

The change in life style with more addiction to fast foods has remarkably reduced the consumption of fruits, vegetables, and legumes. This is because the amount of fiber in diet chart has been found far below the recommended level in any modern society. Most of the studies evaluated multiple benefits of fiber intake on weight reduction along with obesity management where obesity is a risk factor for cardiovascular, diabetics, malignant and metabolic diseases. Considering the benefits of fiber intake, researchers are showing their interest to develop fiber enriched food products by incorporating fruits, vegetables or extracted fiber from different sources into the meal. A focus on obesity management by adding more fruits and vegetables as well as fiber rich products in the diet chart should be recommended.

\section{Conflicts of interest}

The authors declare no conflict of interest.

\section{Acknowledgements}

There were no funding sources for the study.

\section{References}

1. Spiller GA. Definition of dietary fiber. In: Spiller GA editor. Dietary fiber in human nutrition. Boca Raton, Florida, USA: CRC Press; 1993. p. $15-20$.

2. Marlett JA, Mc Burney MI, Slavin JL. Position of the American Dietetic Association:health implications of dietary fiber. Journal of American Dietetic Association. 2002;102:993-1000.

3. Lairon D. Les fibres alimentaires. La Recherche. 1990;21:284-292.

4. Viuda-Martos M, Lopez-Marcos MC, Fermandez-Lopez J, et al. Role of fiber in cardiovascular diseases:a review. Comprehensive reviews in food science and food safety. 2010;9:240-258.

5. Alfieri MA, Pomerleau J, Grace DM, et al. Fiber intake of normal weight, moderately obese and severely obese subjects. Obes Res. 1995;3(6):541547.

6. Pi Sunyer X. The medical risks of obesity. Postgrad Med J. 2009;121(6):21-33.

7. Nguyen T, Lau DC. The obesity epidemic and its impact on hypertension. Can J Cardiol. 2012;28(3):326-333.

8. Ginter E, Simko V. Type 2 diabetes mellitus, pandemic in $21^{\text {st }}$ century. Advances in Experimental Medicine and Biology. 2012;771:42-50.

9. Magnusson RS. Rethinking global health challenges:towards a 'global compact' for reducing the burden of chronic disease. Public Health. 2009;123(3):265-274.

10. Ross A Catharine. Modern Nutrition in Health and Disease. 8th ed. Lea and Febiger Philadelphia; 1994. 1616 p.

11. Galisteo M, Duarte J, Zarzuelo A. 2008) Effects of dietary fibers on disturbances clustered in the metabolic syndrome. $J$ Nutr Biochem. 2008;19(2):71-84.

12. Wong JM, de Souza R, Kendall CW, et al. Colonic health:fermentation and short chain fatty acids. Journal of Clinical Gastroenterology. 2006; $40(3): 235-243$.

13. Cummings JH, Englyst HN. Fermentation in the human large intestine and the available substrates. American Journal of Clinical Nutrition. 1987;45(5):1243-1255.

14. Southgate DAT. Dietary fiber parts of food plants and algae. In: Spiller GA editor. CRC handbook of dietary fiber in human nutrition. Boca Raton, FL: USA: CRC Press; 1993. p. 19-20.

15. Koh-Banerjee P, Rimm EB. Whole grain consumption and weight gain:a review of the epidemiological evidence, potential mechanisms and opportunities for future research. Proc Nutr Soc. 2003;62(1):25-29.

16. Slavin JL. Dietary fiber and body weight. Nutrition. 2005;21(3):411-418.

17. Drewnowski A. Energy density, palatability, and satiety:implications for weight control. Nutr Rev. 1998;56(12):347-353.

18. Liu S, Willett WC, Manson JE, et al. Relation between changes in intakes of dietary fiber and grain products and changes in weight and development of obesity among middle aged women. Am J Clin Nutr. 2003;78(5):920-927.

19. Howarth NC, Saltzman E, Roberts SB. Dietary fiber and weight regulation. Nutr Rev. 2001;59(5):129-139. 
20. Pereira MA, Ludwig DS. Dietary fiber and body-weight regulation. Observations and mechanisms. Pediatr Clin North Am. 2001;48(4):969 980 .

21. Sloan AE. The top ten functional food trends; 2008.

22. Tohill BC. Dietary Intake of Fruit and Vegetables and Management of Body Weight. Background paper for Joint FAO/WHO Workshop on Fruit and Vegetables for Health, Switzerland; 2004. p. 1-3.
23. Rolls BJ, Bell EA. Dietary approaches to the treatment of obesity. Med Clin North Am. 2000;84(2):401-418.

24. Yao M, Roberts SB. Dietary energy density and weight regulation. Nutr Rev. 2001;59(8 Pt1):247-258. 